\title{
Angioplasty of a Persistent sciatic artery: case report
}

\section{Angioplastia de artéria isquiática persistente: relato de caso}

\author{
Denis Szejnfeld', Sergio Quilici Belczak², Igor Rafael Sincos², Ricardo Aun ${ }^{3}$
}

\begin{abstract}
Transluminal balloon angioplasty is a good choice for the treatment of lower limb arterial occlusion. Although there are some guidelines addressing its indications, some situations are so unusual that there is no consensus on their management. The presence of a persistent sciatic artery is a rare congenital anomaly of the circulatory system and may be associated with early atheromatous degeneration and occlusion. The authors describe the case of an 81-year-old woman that presented with a history of rest pain, atrophic lesion and no distal pulses. Angiogram depicted a persistent sciatic artery with segmental occlusion and distal disease. The therapeutic option was balloon angioplasty of the occluded segment, with technical and clinical success at mid-term follow-up.
\end{abstract}

Key words: angioplasty, balloon; atherosclerosis, ischemia.

\section{Resumo}

A angioplastia transluminal com balão tem se mostrado uma boa alternativa no tratamento de oclusões arteriais em membros inferiores. Embora já existam algumas diretrizes quanto à sua indicação, algumas situações ainda são inusitadas e carecem de consenso pela sua raridade. A presença de artéria isquiática persistente é uma anomalia congênita rara do sistema circulatório e pode estar associada com doença ateromatosa precoce e oclusão. Os autores apresentam um caso de uma paciente do sexo feminino de 81 anos, com história de dor de repouso, lesão trófica e ausência de pulsos distais. A arteriografia mostrou persistência de artéria isquiática com oclusão segmentar e doença distal. A abordagem terapêutica escolhida foi angioplastia do segmento ocluído, e o seguimento de médio prazo mostrou sucesso técnico e clínico com esta técnica.

Palavras-chave: angioplastia com balão; aterosclerose; isquemia.

\section{Introduction}

Persistent sciatic artery (PSA) is a rare congenital vascular anomaly, and its prevalence corresponds to 0.01 $0.05 \%$ of the population. It was described by Green in 1832 and first confirmed - using arteriography - by Cowie in $1960^{1,2}$.

This anomalous artery, an atypical extension of the internal iliac artery, provides the major supply of blood to the lower limbs in $63 \%$ of the PSA cases. In such cases, it is the most important artery in the lower limbs, and the superficial femoral artery is hypoplastic or absent ${ }^{3}$.
PSA has a predisposition to form aneurysms, found in $42 \%$ of the cases; about $50 \%$ of which have a complicated progression. They are bilateral in $12-32 \%$ of the cases $^{4,5}$. This anomaly also predisposes to early atheromatous degeneration, distal thromboembolism and arterial occlusion $^{6}$.

Percutaneous transluminal balloon angioplasty is a well established technique for treating significant stenosis and short occlusions. This study describes a case of PSA with atheromatosis and ischemic complications of the left lower limb that was successfully treated using an endovascular technique.

Interventional Radiology Service of the Hospital Brigadeiro, São Paulo (SP)

${ }^{1}$ Full member of Brazilian Society of Interventional Radiology and Endovascular Surgery (SOBRICE); Post-Graduate Student of Master Degree Program in Radiology of the Universidade Federal de São Paulo (UNIFESP); Head of the Endovascular Surgery Service of IGESP Hospital; Attending Physician of Interventional Radiology Service of the Hospital Brigadeiro, São Paulo (SP), Brazil.

${ }^{2}$ Full member of the Brazilian Society of Angiology and Vascular Surgery (SBACV); Post-Graduate Student of Doctorate Program of the School of Medicine of the Universidade de São Paulo

(USP), São Paulo (SP), Brazil; Head of the Vascular Surgery Service of Hospital Geral de Carapicuíba; Carapicuíba (SP), Brazil; Head of the Endovascular Surgery Service of IGESP Hospital; Attending Physician of Interventional Radiology Service of the Hospital Brigadeiro, São Paulo (SP), Brazil.

${ }^{3}$ Full member of the Brazilian Society of Angiology and Vascular Surgery (SBACV); PhD of the School of Medicine of USP, São Paulo (SP); Attending Physician of USP, São Paulo (SP),

No conflicts of interest declared concerning the publication of this article.

Submitted on: 08.12.10. Accepted on: 12.04.11

J Vasc Bras. 2011;10(2):168-172. 


\section{Case report}

An 81-year-old woman presented with a history of rest pain in the left lower limb and trophic ulcers in the first and third toes (Figure 1). The patient, who had a history of hypertension, had no pulses in the left lower limb and no posterior tibial pulse in the right lower limb. The patient was examined by a vascular surgeon, who requested aortography and pelvic and lower limb arteriography. Results revealed that aorta and right iliac system were normal. However, an anomalous artery in the left was shown, which originated in the internal iliac artery and extended inferiorly towards the limb (Figure 2). The superficial femoral artery was hypoplastic (Figure 3). This anomalous artery had several wall abnormalities and was occluded distally at a point close to the transition to the popliteal artery (Figure 4). The anterior and posterior tibial arteries were occluded distally; the fibular artery was pervious, but had moderate stenosis in its proximal third (Figure 5).

The hypothesis was raised from persistent sciatic artery with atheromatous degeneration and an occluded segment. Endovascular treatment was suggested for obstructive lesion. Using a contralateral approach and a $45-\mathrm{cm}$-long $6 \mathrm{~F}$ introducer sheath, a 0.018 guidewire was advanced through the obstruction. Angioplasty was performed using a $5 \times 20$ $\mathrm{mm}$ balloon (Figure 6). The fibular artery was also submitted to angioplasty using a $3 \times 120 \mathrm{~mm}$ balloon (Figure 7). Follow-up arteriogram showed that the artery was pervious and contrast medium flow rate was good (Figure 8).

Dual antiplatelet therapy was initiated with $100 \mathrm{mg}$ /day of acetyl salicylic acid and clopidogrel at $300 \mathrm{mg}$ loading dose and $75 \mathrm{mg} /$ day thereafter. Immediately after surgery,

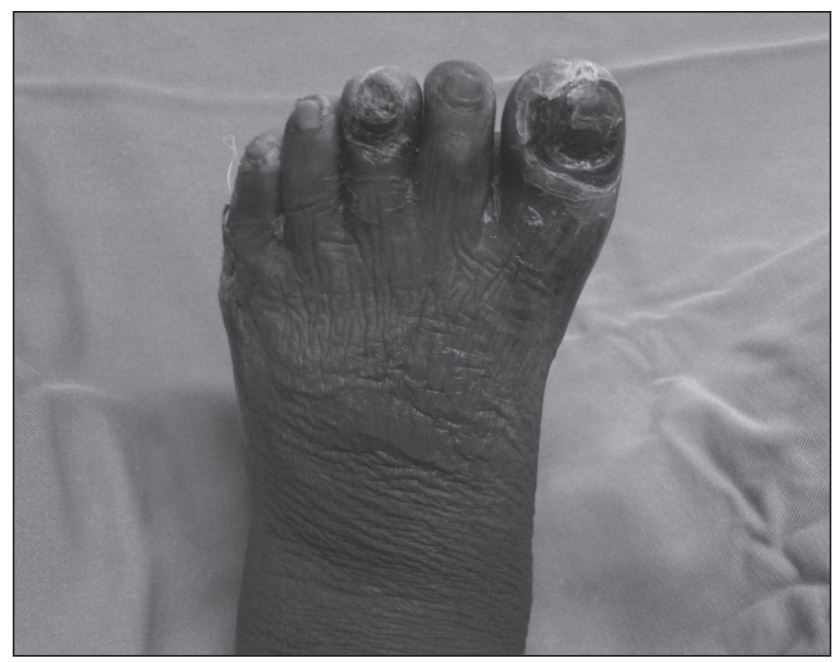

Figure 1 - Image shows trophic ulcers in foot. the patient reported pain relief. She is currently being followed-up in our outpatient service. At 90 days after the endovascular procedure, trophic lesions did not progressed and the patient has no pain.

\section{Discussion}

PSA is a vascular anomaly whose origin is well known. Embryos reach $9 \mathrm{~mm}$ at about the 6th week. In this phase, the sciatic artery, or axial artery, arises from the dorsal root of the umbilical artery and becomes the major source of blood to the primitive foot. When the embryo is $10 \mathrm{~mm}$ long, the femoral system starts to develop as a continuation of the external iliac artery, which expands and branches out to irrigate the thigh. When the embryo reaches $14 \mathrm{~mm}$, at about 8 weeks, the lower limb has a dual blood supply system, the sciatic and the femoral ones. At about 12 weeks, the sciatic artery involutes, and the superficial femoral artery develops. In adults, remnants of the sciatic artery participate in the formation of gluteal arteries, popliteal artery, and the origin of anterior tibial and fibular arteries, and contribute to the terminal anastomosis of the foot ${ }^{1,2,7}$.

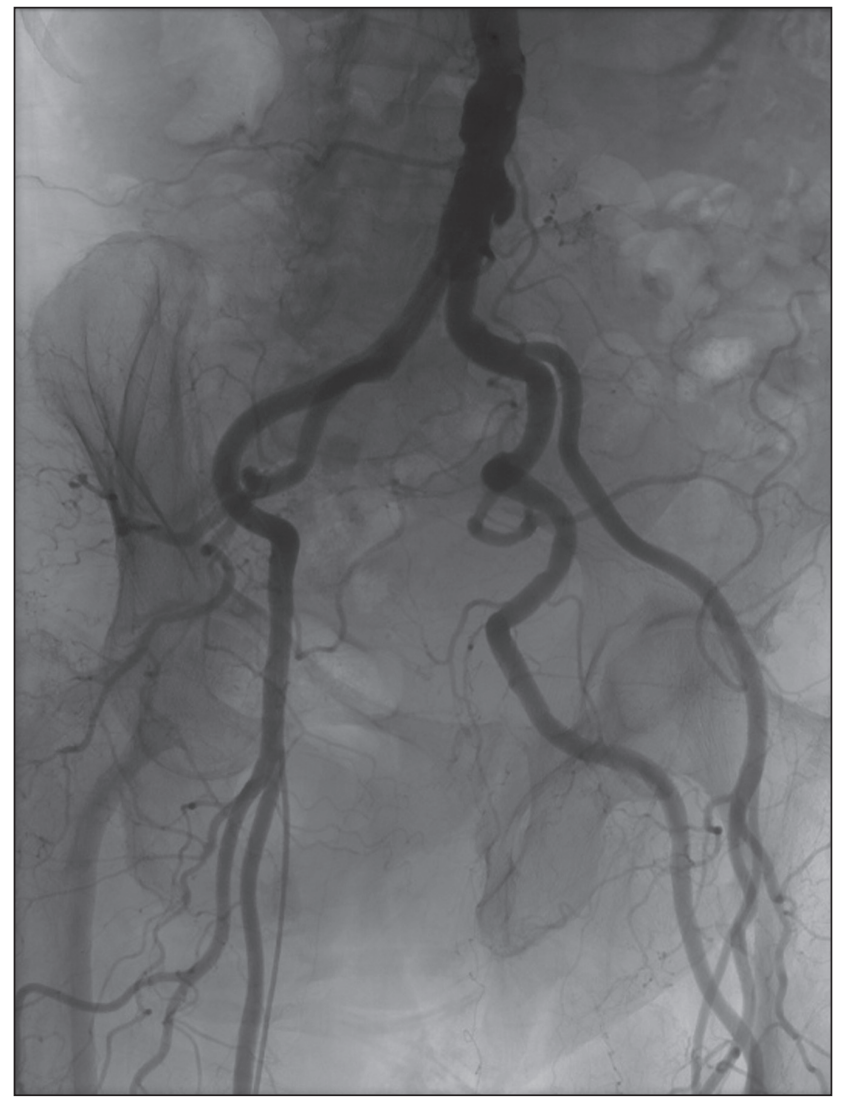

Figure 2 - Arteriogram shows sciatic artery arising from left internal iliac artery. 


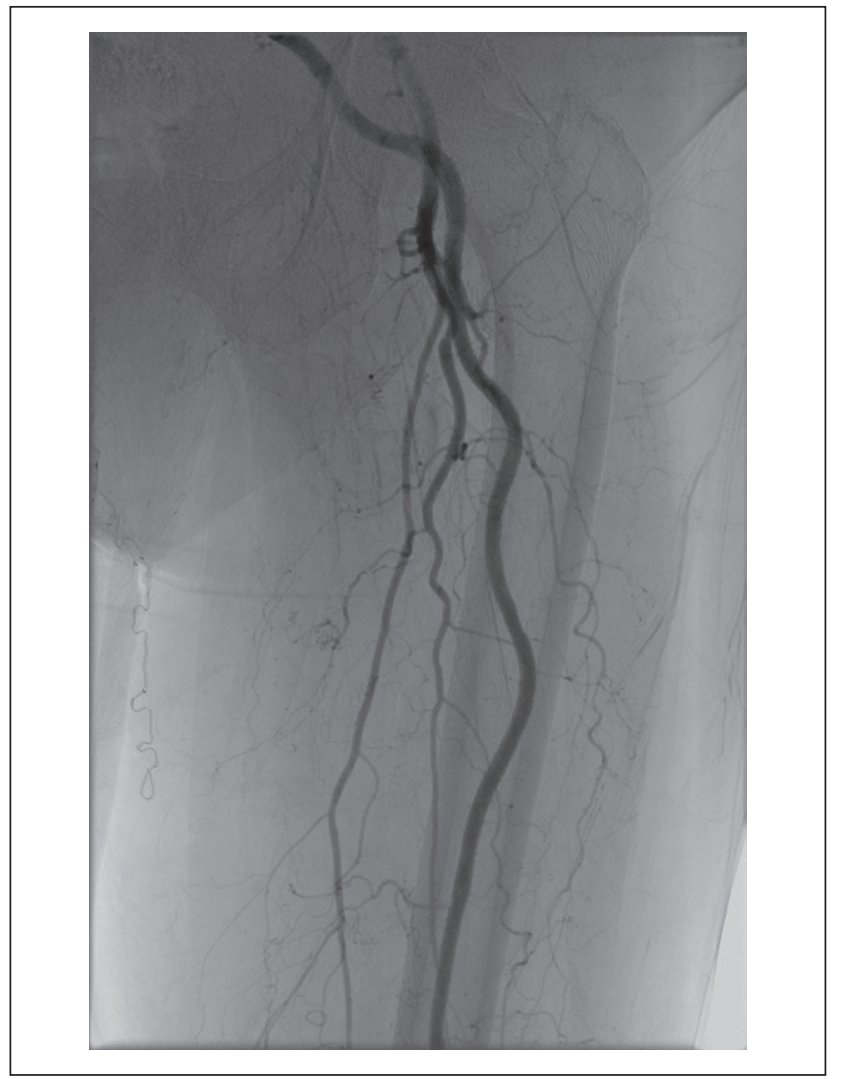

Figure 3 - Arteriogram shows hypoplastic superficial femoral artery.

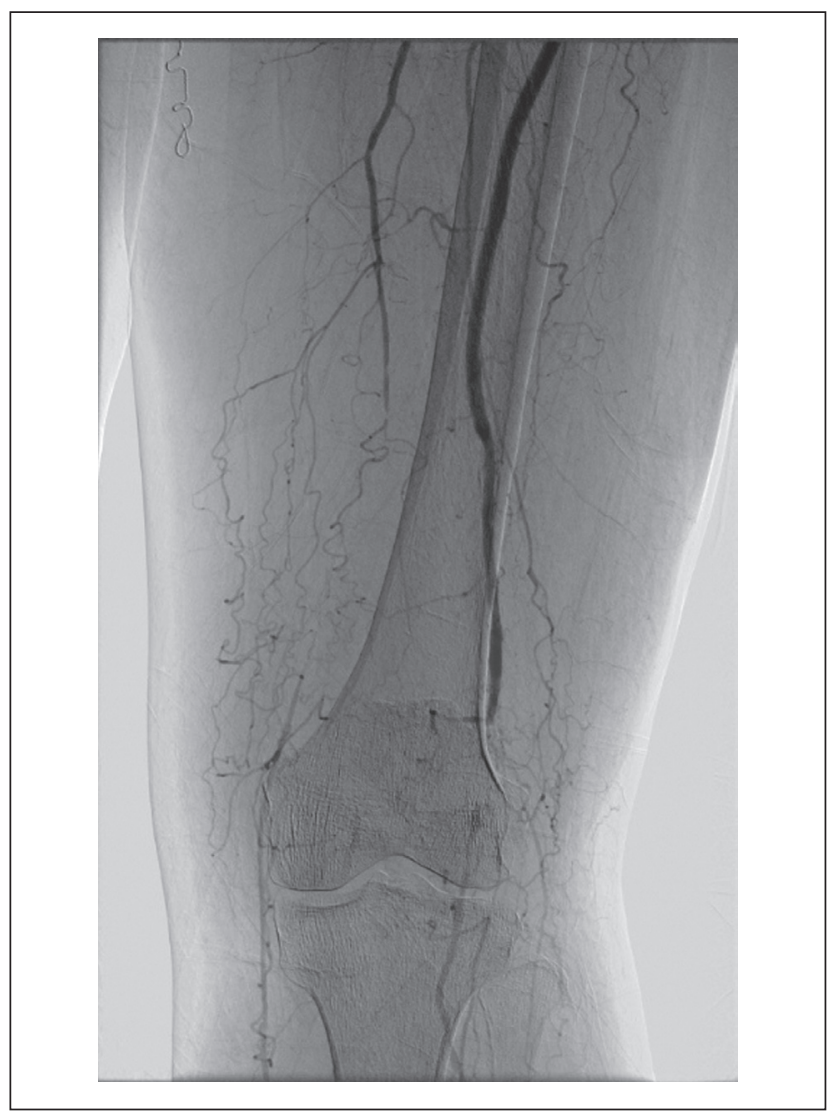

Figure 4 - Arteriogram shows site of arterial occlusion.

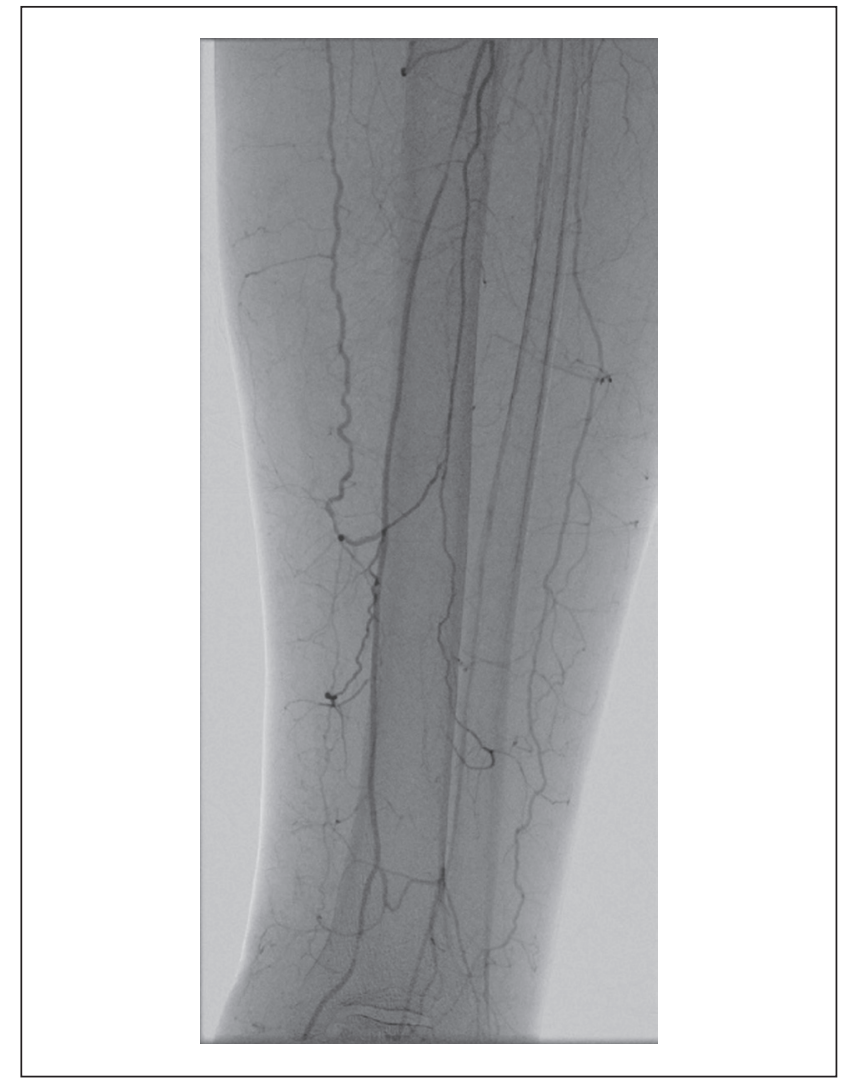

Figure 5 - Arteriogram confirms atherosclerotic occlusion of leg arteries.

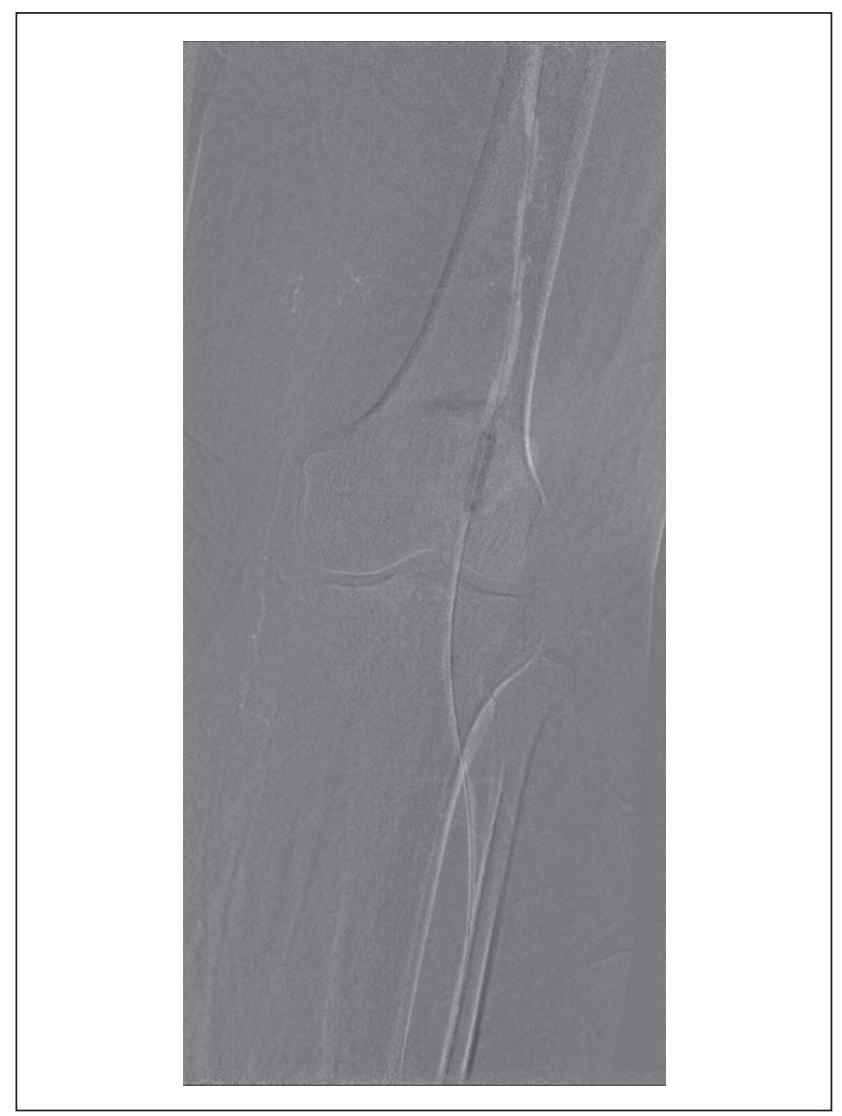

Figure 6 - Angioplasty of sciatic artery using $5 \times 20 \mathrm{~mm}$ balloon. 


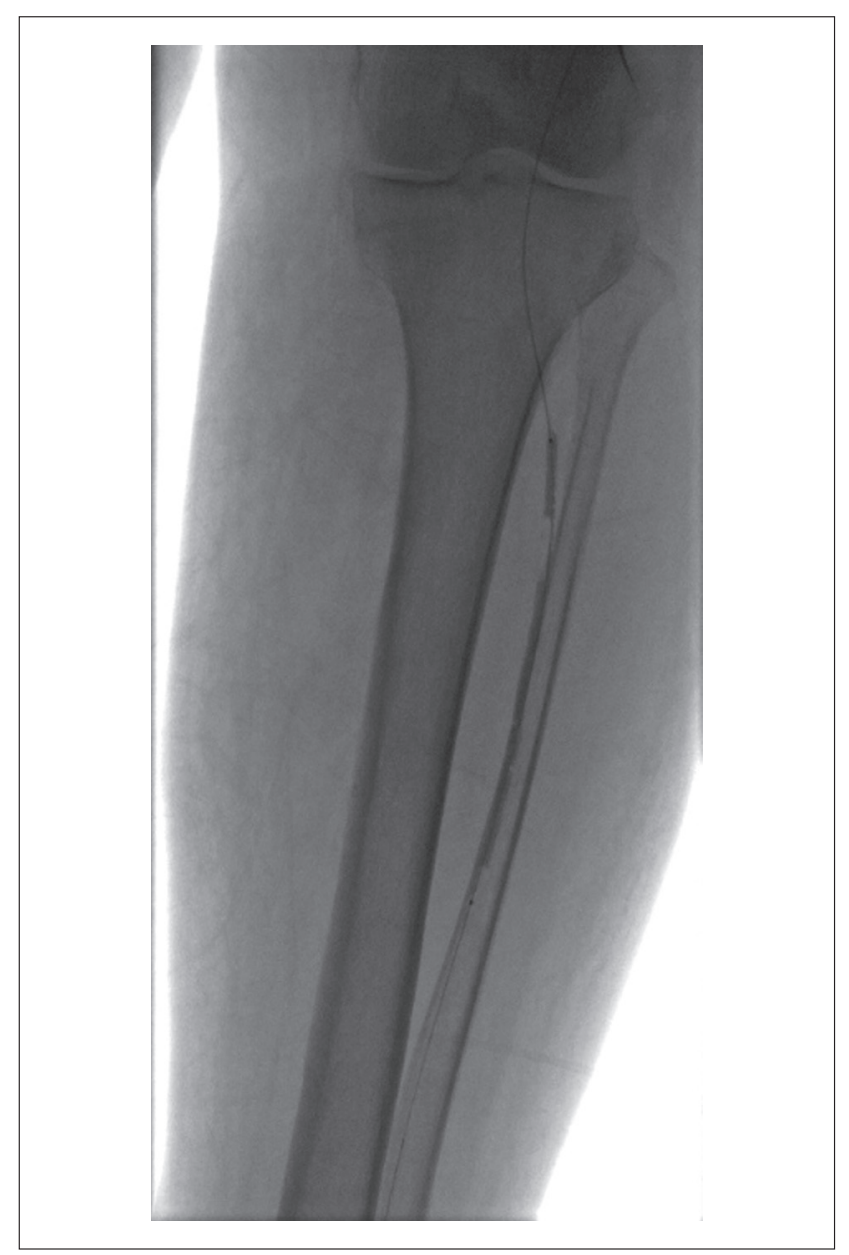

Figure 7 - Angioplasty of fibular artery using $3 \times 120$ mm balloon.

PSA has two different presentations:

- complete (63-79\% of the cases), in which this artery is the major blood supply to the lower limb, and the superficial femoral system is hypoplastic, but rarely absent. This is the presentation found in the case reported here ${ }^{4}$.

- incomplete (about $20 \%$ of the cases), in which PSA is hypoplastic and communicates via several branches with the femoral system, which, in this case, has no abnormalities ${ }^{8}$.

There is no difference in incidence between sexes, and bilateral incidence is about $12 \%$. The anomalous artery follows the trajectory of the sciatic nerve to the distal thigh. There are associations with other malformations, such as neurofibromatosis, bone hypertrophy, single kidney and other arterial and venous anomalies ${ }^{2}$. PSA is usually symptomatic and associated with aneurysm formation, which is

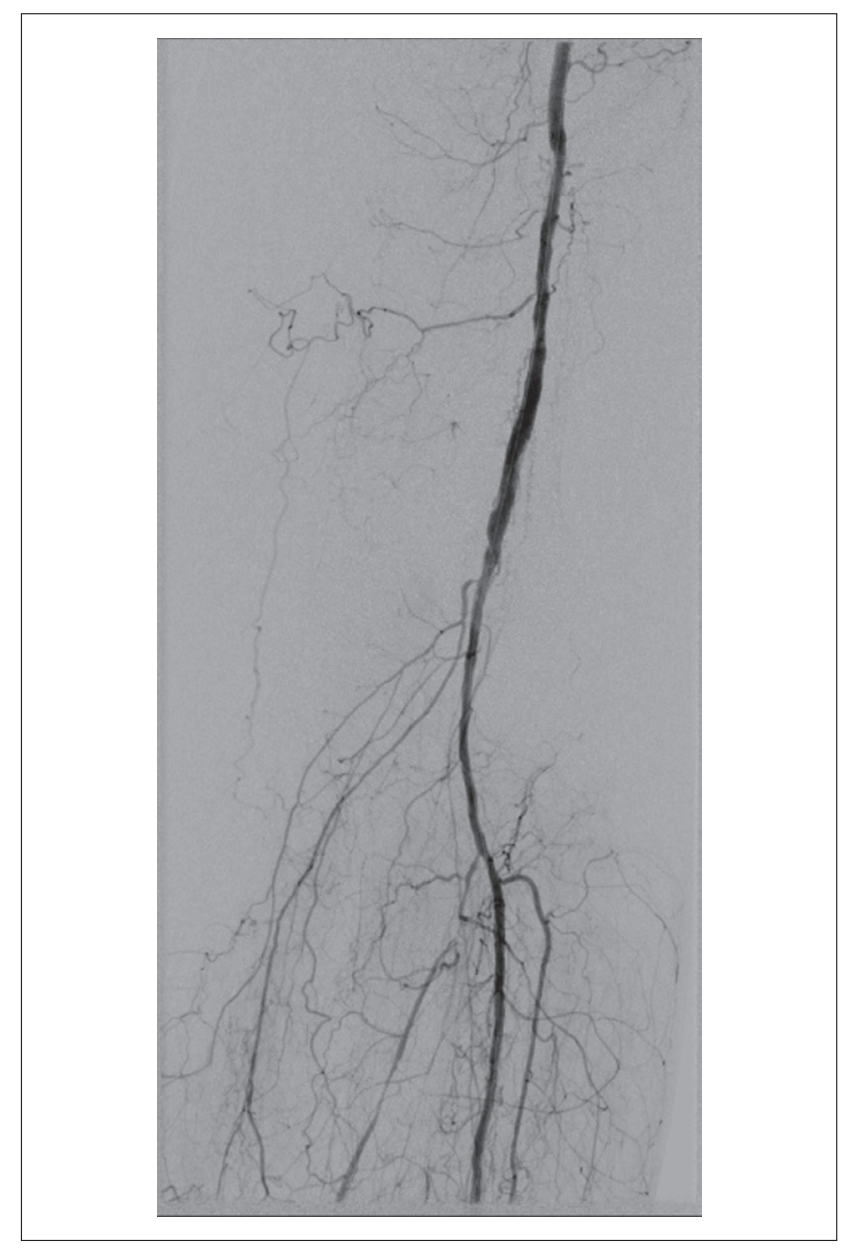

Figure 8 - Control arteriogram confirms good results of treatment.

seen in $25-58 \%$ of the cases. This high incidence of aneurysms is assigned to repeated micro traumas in the gluteal area and to hypoplasia of elastin fibers in the arterial wall ${ }^{9,10}$. Another possible symptom is acute or chronic ischemia due to accelerated atherosclerotic disease and consequent thromboembolism ${ }^{11}$.

The diagnosis may be suspected if a patient presents with reduced or absent femoral pulse but palpable popliteal and distal pulses associated or not with a pulsatile gluteal mass $^{12}$. The differential diagnosis should include lumbosciatalgia, arteriovenous fistula, gluteal abscess and, principally, gluteal artery aneurysm².

Digital subtraction arteriography is the standard criterion for the diagnosis of PSA. The iliac arteries, femoral system and distal arteries should also be examined to plan treatment accurately. Other studies, such as computerized tomography (CT) angiography, MR angiography and Doppler ultrasound may also be useful. 
There is no consensus in the literature about the best therapy for this entity, and treatments should be selected for each specific case. Some reports describe the use of several grafts, synthetic prosthesis and autologous veins, and results have been good ${ }^{12-14}$. There are also a few reports of successful endovascular treatment using thrombolysis, embolization, covered stents and angioplasty ${ }^{10,13,15}$.

In the case described here, the occluded segment and the distal vascularization suggested the use of balloon angioplasty and, according to the results of angiographic follow-up that showed the artery was pervious and there was a good contrast medium flow rate, we decided not to use stents. Distal angioplasty of the fibular artery was necessary to improve distal circulation and to ensure better chances of success. The immediate improvement of pain symptoms, reported by the patient immediately after operation and three months later, confirmed the success of the treatment used.

\section{Conclusion}

PSA is a rare vascular anomaly and should be included in the differential diagnosis of lower limb vascular diseases. Arteriography, the standard criterion for the diagnosis of this condition, is a useful aid in its treatment planning. Several treatment options are available and should be chosen individually for each specific case. The endovascular approach combined with angioplasty is a possible alternative for the treatment of this condition.

\section{References}

1. Jung AY, Lee W, Chung JW, et al. Role of computed tomographic angiography in the detection and comprehensive evaluation of persistent sciatic artery. J Vasc Surg. 2005;42:678-83.

2. Juliá J, Rimbau EM, Gómez F, Lozano P, Corominas C. Arteria ciática persistente bilateral. Rev Angiol. 1995;4:199-205.

3. Kempinas WG. O desenvolvimento do sistema vascular. In: Maffei FHA, Lastória S, Yoshida WB, Rollo HA. Doenças vasculares periféricas. $3^{\text {a }}$ ed. Rio de Janeiro: Medsi; 2002. p. 16-7.

4. Wilson JS, Bowser AN, Miranda A, et al. Limb ischemia associated with persistent sciatic artery aneurysms-a report of 2 cases. Vasc Endovascular Surg. 2005;39:97-101.
5. Chleboun JO, Teasdale JE. A pulsatile gluteal mass due to sciatic artery aneurysm. Aust N Z J Surg. 1995;65:907-10.

6. Bez LG, Costa-Val R, Bastianetto P, et al. Persistência da artéria isquiática: relato de caso. J Vasc Bras. 2006;5:233-6.

7. Hassan A. Symptomatic persistent sciatic artery. J Am Coll Surg. 2004;199:171-3.

8. Maldini G, Teruya TH, Kamida C, Eklof B. Combined percutaneous endovascular and open surgical approach in the treatment of a persistent sciatic artery aneurysm presenting with acute limbthreatening ischemia--a case report and review of the literature. Vasc Endovascular Surg. 2002;36:403-8.

9. Fearing NM, Ammar AD, Hutchinson SA, Lucas ED. Endovascular stent graft repair of a persistent sciatic artery aneurysm. Ann Vasc Surg. 2005;19:438-41.

10. Mathias KD, Feldmüller M, Haarmann P, Goldbeck F. Persistent sciatic artery: bilateral percutaneous transluminal angioplasty in ischemic disease. Cardiovasc Intervent Radiol. 1993;16:377-9.

11. Ishida K, Imamaki M, Ishida A, Shimura H, Miyazaki M. A ruptured aneurysm in persistent sciatic artery: a case report. J Vasc Surg. 2005;42:556-8.

12. Nunes MA, Ribeiro RM, Aragão JA, Reis FP, Feitosa VL. Diagnóstico e tratamento de aneurisma da artéria isquiática persistente: relato de caso e revisão da literatura. I Vasc Bras. 2008;7:66-71.

13. Ito $\mathrm{H}$, Okadome $\mathrm{K}$, Odashiro $\mathrm{T}$, et al. Persistent sciatic artery: two case reports and a review of the literature. Cardiovasc Surg. 1994;2:275-80.

14. Urayama $\mathrm{H}$, Tamura M, Ohtake H, Watanabe Y. Exclusion of a sciatic artery aneurysm and an obturator bypass. J Vasc Surg. 1997;26:697-9.

15. Loh FK. Embolization of a sciatic artery aneurysm an alternative to surgery: a case report. Angiology. 1985;36:472-6.

Correspondence: Sergio Quilici Belczak Rua Sabará, 47 - Higienópolis CEP 04515-030 - São Paulo (SP), Brazil E-mail: belczak@gmail.com

Authors contribution: Conception and design: SQB Analysis and interpretation: DS, IRS Data collection: IRS, DS Writing the article: SQB, DS Critical revision of the article: IRS Final approval of the article*: DS, IRS General responsibility for the study: DS Information about funding: N/A *All authors have read and approved the final version of the article submitted on J Vas Bras. 